\title{
Research on the process of biomass compaction in the form of straw
}

\author{
Dominik Wilczyński ${ }^{1,}$, Ireneusz Malujda ${ }^{1}$, Jan Górecki ${ }^{1}$, and Piotr Jankowiak ${ }^{1}$ \\ ${ }^{1}$ Poznan University of Technology, Chair of Basics of Machine Design, Piotrowo Str. 3, Poland
}

\begin{abstract}
The paper presents the examination of the degree of compaction of biomass material in the form of straw, depending on the temperature of the compaction process, the diameter of the pressing punch and the humidity of the compacted straw. The series of punch-sleeve assemblies characterized by the variable diameter of both the punch and the sleeve were used in the tests. For each diameter of the sleeve, a straw sample was compressed with a force suitable to obtain a compressive stress value in the sample cross section of $10 \mathrm{MPa}$. Each punch-sleeve assembly was adapted for installation on a strength machine, mounting temperature sensors and for mounting on the surface of a cylindrical sleeve, a coil heater. Wheat-rye straw was used in the research. The tests carried out are to constitute guidelines for the construction of biomass compaction machines.
\end{abstract}

Keywords: biomass, natural polymers, relative density, degree of compaction

\section{Introduction}

The global trend is to systematically increase the degree of utilization of biomass as a source of energy, as well as its other applications [1]. Wooden biomass if broken down form, i.e. sawdust, can have a practical application in furniture and construction industries [2]. This is enabled by various technological processes of compacting loose wooden biomass [3, 4]. An example of such processes is pressing the biomaterial in elevated temperature, as well as other agglomeration methods employing techniques based on piston or screw compaction [3-5]. In order for the listed compaction processes to provide a final product with the required physical and chemical properties, it is necessary to identify the properties of the biomass to select the characteristics that are beneficial for the compaction process (temperature, compaction force, biomass humidity, degree of biomass fragmentation and compaction method used) [2].

As mentioned earlier, the biomass is utilized as an energy source [6]. Uncompacted biomass is characterized by low density, in the range of $100-200 \mathrm{~kg} / \mathrm{m}^{3}$ [7]. This severely limits the possibility of storage and transportation [6]. The compaction process allows to obtain agglomerated material with much higher density $[7,8]$. The multiple aspects of the

\footnotetext{
* Corresponding author: dominik.wilczynski@put.poznan.pl

Reviewers: Grzegorz Domek, Darina Ondrušowá
} 
essential characteristics of this process have been touched upon by numerous papers, including [1, 3, 4, 9-14]. The factors influencing the resistance and durability of the agglomerate include the type of compacted biomass (materials), moisture content, size and distribution of particles, process temperature, additives such as binding agent and others as well as the parameters of the compaction process (temperature, size of pressure face, pressure face traverse velocity, etc.) $[14,15]$. As previously mentioned, the particle size affects the quality of the agglomerate. The process to break down the biomass and its further course is therefore highly relevant for the subsequent compaction [7, 9, 16, 17].

The present paper presents the study of the compaction of biomass in form of straw. The compacted straw material is triticale. The study employed an agglomeration station of the author's own design and construction. The construction details, methodology and the course of the study is discussed below. Further chapters of the study present example results of the experiment together with conclusions.

\section{Testing station and methodology}

Before commencing the study, the straw was broken down using the cutting station presented on Fig. 1. The station consists of two assemblies. The first one is an arrangement of cylinders which take in and press the material, transporting it to the cutting zone 2 . At this location, the arrangement of blade and counter-blade cuts the material. Each of the assemblies has its own electrical power supply controlled by inverters 8 and 9 .

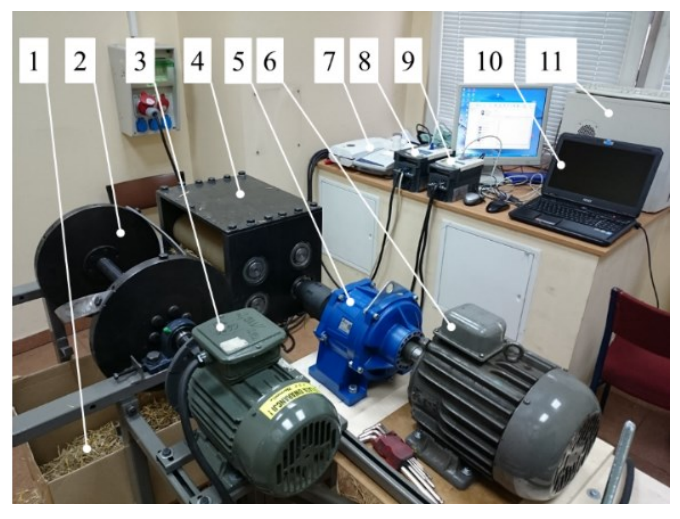

Fig. 1. Biomass material cutting station: 1 - cut biomass material, 2 - cutting knives assembly, 3 - electrical motor powering the rotational movement of the cutting knives, 4 - roller assembly, 5 - reduction gear for the roller assembly, 6 - electrical motor powering the roller assembly, 7 - weight-drier, 8 - electrical motor inverter for the roller assembly, 9 - electrical motor inverter for the cutting knives assembly, 10 - computer for registering the working parameters of the cutting knife assembly electrical motor, 11 - computer for registering the working parameters of the roller assembly electrical motor [9]

The broken down material (Fig. 2.) was utilized in testing the degree of compaction. 


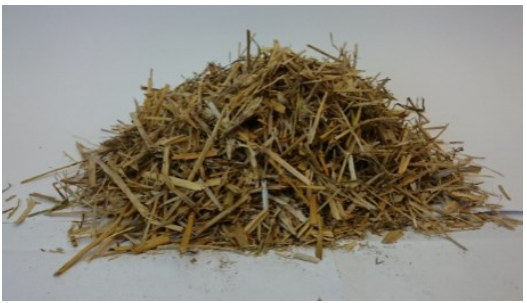

Fig. 2. General view of the cut straw [9]

The broken down straw prepared for the purpose of the study was characterized by two levels of moisture. The straw with average humidity equal to $16.94 \%$ was compacted first. Such humidity was exhibited by straw supplied directly from the field in form of a bale. In order to examine the compaction of straw with greater humidity, it was subject to seasoning before fragmentation in special containers (Fig. 3).

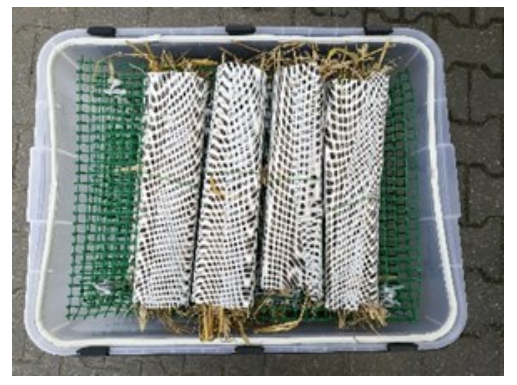

Fig. 3. View of the container with straw intended for seasoning

In the course of the seasoning process which lasted for $648 \mathrm{~h}$, the straw achieved average humidity equal to $28.75 \%$. Fig 4 presents the change in humidity value in the course of the seasoning process.



Fig. 4. The change of straw humidity in the course of seasoning [9]

To record the straw humidity, a weight-drier device was employed (Fig. 5). 


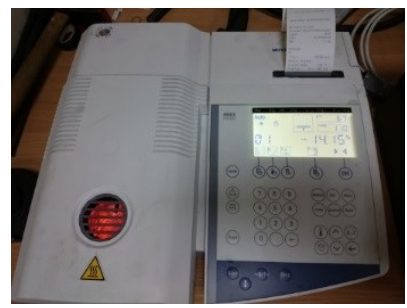

Fig. 5. Weight-drier used to measure the straw humidity before fragmentation [9]

For the study of the compaction process, a series of sleeve - die assemblies were used (Fig. 6). A single assembly consists of a die 1, sleeve 2, coil heater 3 and temperature sensors 4 built into the sleeve sides. The coil heaters together with the sensors were used to heat up the straw before starting the examination of the influence of the change in temperature on compaction parameters. The compaction was performed sequentially in temperatures: room temperature $\sim 25^{\circ} \mathrm{C}, 50^{\circ} \mathrm{C}, 100^{\circ} \mathrm{C}, 150^{\circ} \mathrm{C}$ and $200^{\circ} \mathrm{C}$. The sleeve diameters were, respectively: $\varnothing 30 \mathrm{~mm}, \varnothing 40 \mathrm{~mm}, \varnothing 50 \mathrm{~mm}, \varnothing 60 \mathrm{~mm}, \varnothing 70 \mathrm{~mm}$ and $\varnothing 80 \mathrm{~mm}$.

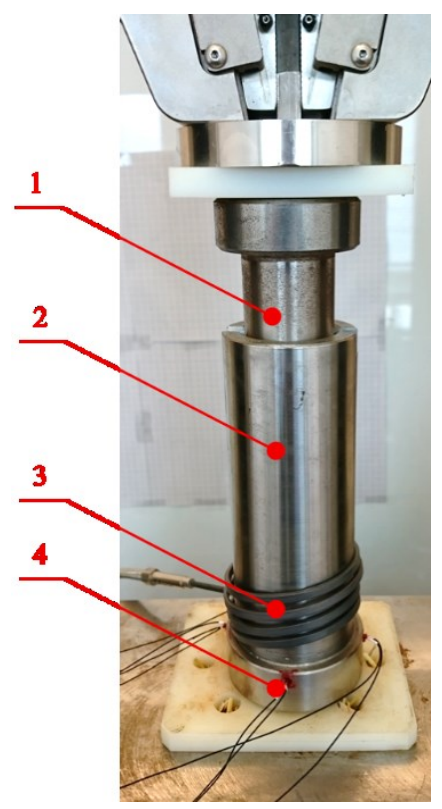

Fig. 6. The sleeve-die assembly used to compact the broken down straw: $1-$ die, 2 - sleeve, 3 - coil heater, 4 - temperature sensors

In order to achieve the value of compressive stress equal to $10 \mathrm{MPa}$ for the sample's cross section, together with the increase in sleeve diameter, the sample also had to be compressed with sufficient force exerted by the strength testing machine MTS Insight 50 $\mathrm{kN}$. The table below lists the force values for specific sleeve diameters. 
Table 1. Breakdown of force values for different sleeve diameters required to achieve the compressive stress of $10 \mathrm{MPa}$

\begin{tabular}{|c|c|c|c|c|c|c|c|}
\hline \multirow{\sigma}{\sigma_{\mathbf{c}}=10[\mathrm{MPa}]}{} & $\begin{array}{c}\text { Sleeve } \\
\text { diameter } \\
{[\mathbf{m m}]}\end{array}$ & $\boldsymbol{\varnothing 3 0}$ & $\boldsymbol{\varnothing 4 0}$ & $\boldsymbol{\varnothing 5 0}$ & $\boldsymbol{\varnothing 6 0}$ & $\boldsymbol{\varnothing 7 0}$ & $\boldsymbol{\varnothing 8 0}$ \\
\cline { 2 - 7 } & $\begin{array}{c}\text { Area } \\
{\left[\mathbf{m m}^{2}\right]}\end{array}$ & 706.9 & 1256.6 & 1963.5 & 2827.4 & 3848.5 & 5026.6 \\
\hline & Force [N] & 7068.6 & 12566.4 & 19634.9 & 28274.3 & 38484.5 & 50265.5 \\
\hline
\end{tabular}

For every variable compacting process parameter value, i.e. sleeve diameter, temperature and humidity, the examination was repeated three times.

Further in the study the results of the examination were presented and discussed.

\section{Examination results and analysis}

Table 2 shows example results of the examination of the degree of compaction of straw with average humidity equal to $16.94 \%$, in a sleeve with diameter $\varnothing 30 \mathrm{~mm}$. The state under load means that the compacted sample is compressed with force as in table 1 exerted by the strength testing machine. Relieved state means that no force is applied to the sample.

Table 2. Breakdown of example average degrees of compression of straw average humidity of $16.94 \%$ for compaction in sleeve with diameter $\varnothing 30 \mathrm{~mm}$

\begin{tabular}{|c|c|c|}
\hline $\begin{array}{c}\text { Temperature } \\
{\left[{ }^{\circ} \mathrm{C}\right]}\end{array}$ & State under load & Relieved state \\
\hline $\begin{array}{c}\text { ambient } \\
\approx 25\end{array}$ & 3.24 & 2.77 \\
\hline 50 & 3.29 & 2.75 \\
\hline 100 & 3.27 & 2.68 \\
\hline 150 & 3.55 & 2.96 \\
\hline 200 & 3.33 & 2.85 \\
\hline
\end{tabular}

The figure below presents an example view of compacted straw samples in different temperatures with average humidity $16.94 \%$, in a sleeve with diameter $\varnothing 80 \mathrm{~mm}$. Viewed from the left side, we see a sample contacted in ambient temperature of approx. $25^{\circ} \mathrm{C}$, next samples compacted in temperatures $50^{\circ} \mathrm{C}, 100^{\circ} \mathrm{C}, 150^{\circ} \mathrm{C}$ and $200^{\circ} \mathrm{C}$.
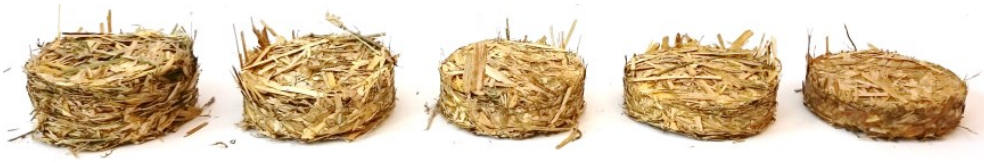

Fig. 7. General view of compacted samples obtained from straw with average humidity $16.94 \%$ in sleeve with internal diameter $\varnothing 80 \mathrm{~mm}$, processed in ambient temperature, $50^{\circ} \mathrm{C}, 100^{\circ} \mathrm{C}, 150^{\circ} \mathrm{C}$ and $200^{\circ} \mathrm{C}$

Fig. 8 shows the characteristics of change in the compaction degree of straw with average humidity $16.94 \%$ depending on the sleeve diameter value and temperature. 


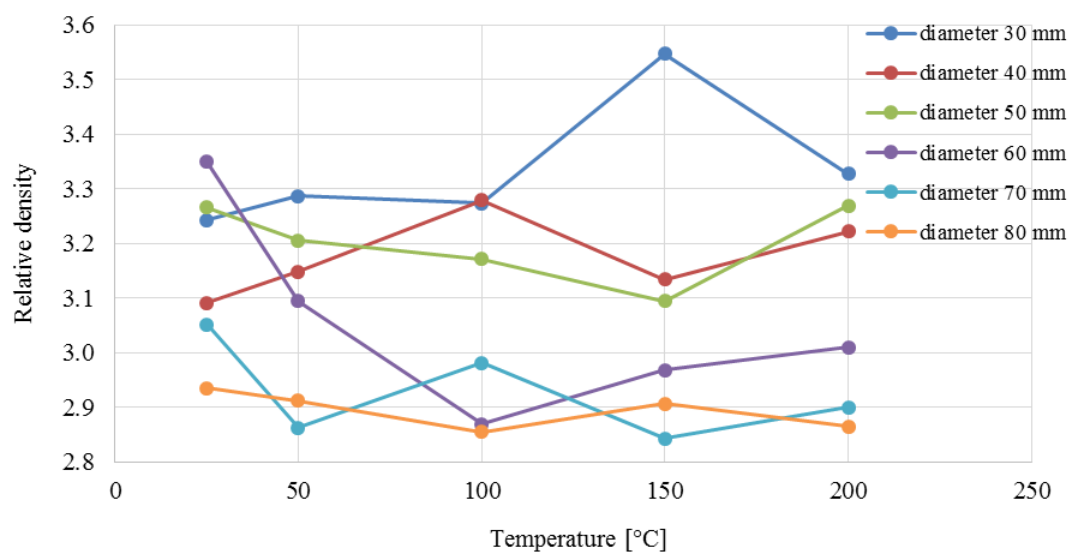

Fig. 8. Characteristics of change in the compaction degree of straw with average humidity of $16.94 \%$ under different temperatures during course the compaction process and sleeve diameters - state under load

Based on the above characteristics, the following conclusions were drawn:

- the increase in sleeve diameter causes a decrease in the degree compaction,

- a noticeable division between the degree of compaction in diameter ranges Ø30-Ø50 $\mathrm{mm}$ and Ø60-Ø80 $\mathrm{mm}$ is observed,

- no unambiguous tendency to decrease the degree of compaction together with the increase in temperature for specific sleeve diameter ranges is observed, with the exception for sleeve diameter $\varnothing 60 \mathrm{~mm}$,

- sleeve diameters $\varnothing 60 \mathrm{~mm}, \varnothing 70 \mathrm{~mm}$ and $\varnothing 80 \mathrm{~mm}$ exhibit a slight decrease in the degree of compaction together with the increase of temperature,

- sleeve diameters $\varnothing 30 \mathrm{~mm}, \varnothing 40 \mathrm{~mm}$ and $\varnothing 50 \mathrm{~mm}$ exhibit no tendency to reduce the degree of compaction together with the increase in temperature,

- the sudden increase in the degree of compaction for sleeve diameter $\varnothing 30 \mathrm{~mm}$ and compaction temperature $150^{\circ} \mathrm{C}$ can be accounted for by the non-homogenous compacted straw sample,

- for diameters $\varnothing 50-\varnothing 80 \mathrm{~mm}$, the degree of compaction decreases together with the increase in temperature until the value $150^{\circ} \mathrm{C}$,

- for sleeve diameters $\varnothing 30-\varnothing 50 \mathrm{~mm}$, during compaction in temperature equal to $200^{\circ} \mathrm{C}$ there is an observable slight increase in the degree of compaction.

Fig. 9 shows the characteristics of the change in the degree of straw compaction with average moisture $16.94 \%$ depending on the sleeve diameter value and temperature while in relieved state. 


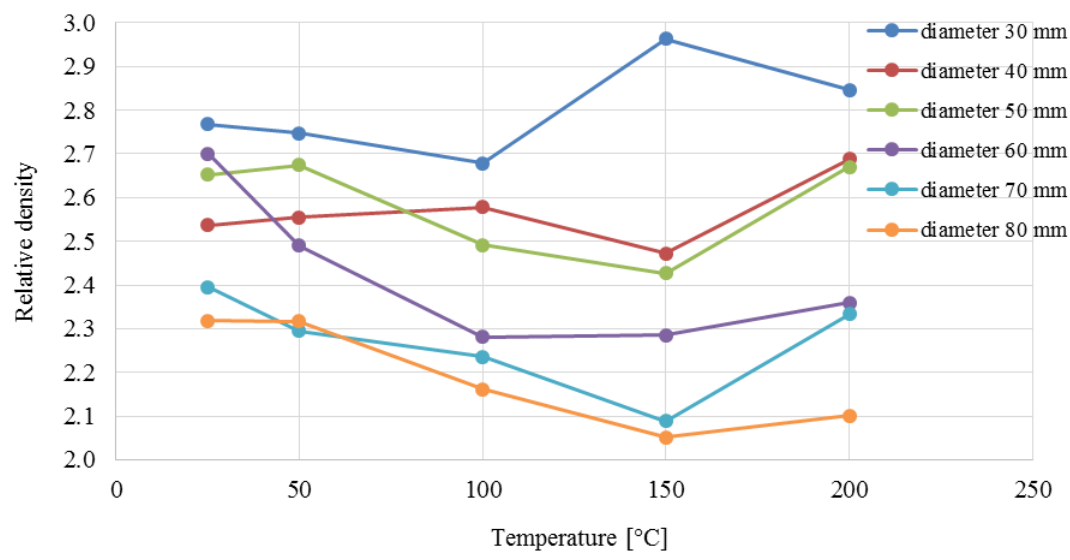

Fig. 9. The characteristics of change in the degree of compaction of straw with humidity $16.94 \%$ for different temperatures of the compaction process and sleeve diameters - relieved state

Based on the characteristics presented on Fig. 9, the following conclusions were drawn:

- for the relieved state, the degree of compaction decreases for all the process parameter values in comparison to the loaded state. This can be accounted for by the increase of sample volume in the relieved state,

- in the case of diameters $\varnothing 30, \varnothing 40$ and $\varnothing 50 \mathrm{~mm}$, there is a slight tendency for the degree of compaction to increase together with the increase of temperature,

- a sudden increase in the degree of compaction for sleeve diameter $\varnothing 30 \mathrm{~mm}$ and compaction temperature of $150^{\circ} \mathrm{C}$ can be accounted for by the non-homogenous nature of straw sample and the influence of elevated temperature,

- for diameters $\varnothing 60, \varnothing 70$ and $\varnothing 80 \mathrm{~mm}$ there is an observable decreasing trend for the degree of compaction as the temperature increases - this can be accounted for by the influence of the intensive water evaporation from straw which causes an increase in the volume of compacted sample,

- for diameters $\varnothing 50-\varnothing 80 \mathrm{~mm}$, the degree of compaction decreases together with the increase of temperature until the value of $150^{\circ} \mathrm{C}$. For temperature $200^{\circ} \mathrm{C}$, it can be estimated that the water in the porous straw material evaporates fast enough to allow for more compaction.

Fig. 10 shows an example breakdown of straw samples compacted in different temperatures with average humidity of $28.75 \%$, in a sleeve diameter $\varnothing 40 \mathrm{~mm}$. Looking from the left to the right side, we see samples compacted in room temperature equal to approx. $25^{\circ} \mathrm{C}$, and further on in temperatures $50^{\circ} \mathrm{C}, 100^{\circ} \mathrm{C}, 150^{\circ} \mathrm{C}$ and $200^{\circ} \mathrm{C}$.

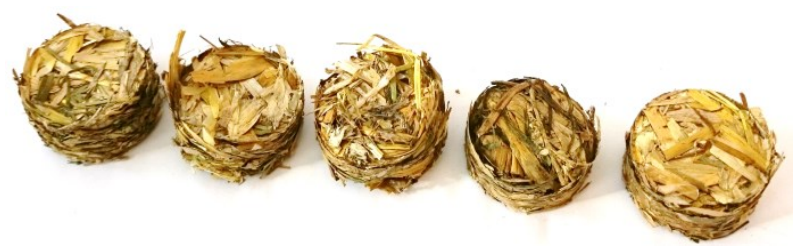

Fig. 10. General view of compacted straw samples with average humidity of $28.75 \%$ obtained in the sleeve with internal diameter of $\varnothing 40 \mathrm{~mm}$, and in the following temperatures: ambient $\sim 25^{\circ} \mathrm{C}, 50^{\circ} \mathrm{C}$, $100^{\circ} \mathrm{C}, 150^{\circ} \mathrm{C}$ and $200^{\circ} \mathrm{C}$

Fig. 11 shows the characteristics of the change in the degree of compaction for straw with average moisture of $28.75 \%$ depending on the sleeve diameter value and temperature. 




Fig. 11. Characteristics of change in the degree of compaction of straw with relative humidity of $28.75 \%$ for different temperatures of the compaction process and sleeve diameters - state under load

According to the above drawing, one can determine as follows:

- with the increase of temperature to $100^{\circ} \mathrm{C}$, there is an observed tendency for the degree of compaction to decrease for all sleeve diameters,

- for sleeve diameters from $\varnothing 50-\varnothing 80 \mathrm{~mm}$ the decreasing trend for the degree of compaction is maintained until the compaction temperature value $150^{\circ} \mathrm{C}$, and for sleeves with diameters $\varnothing 60, \varnothing 70$ and $\varnothing 80 \mathrm{~mm}$, this tendency is maintained for temperature value $200^{\circ} \mathrm{C}$.

Fig. 12 shows the characteristics of the change in the degree of compaction of straw with average humidity of $28.75 \%$ depending on sleeve diameter and temperature, relieved state.

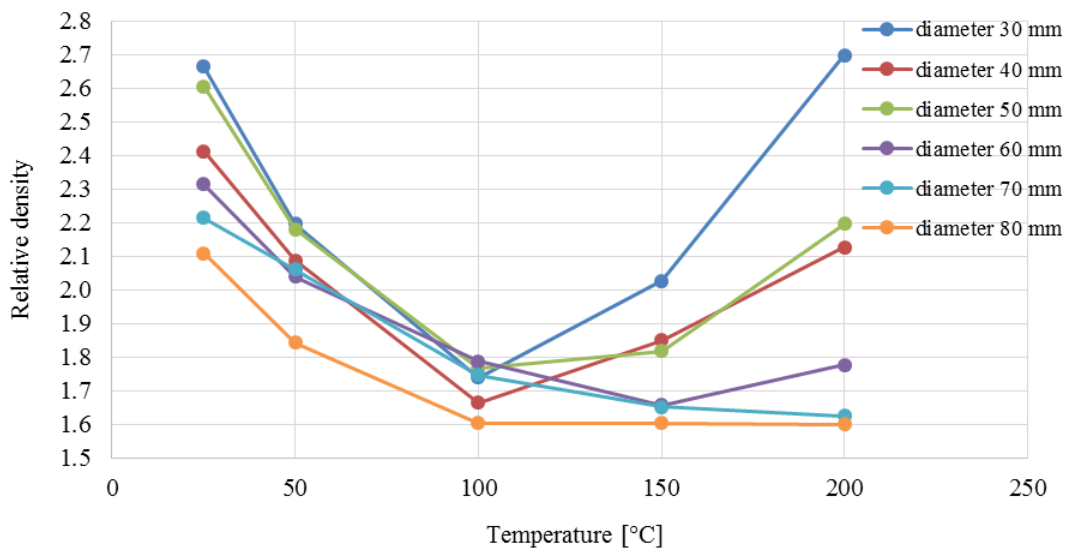

Fig. 12. Characteristics of the change of compaction of straw with average humidity of $28.75 \%$ for different temperatures of the compaction process and sleeve diameters - relieved state

The data on Fig. 12 allows to draw the following conclusions:

- together with the increase of temperature to $100^{\circ} \mathrm{C}$, we observe a significant tendency to reduce the degree of compaction for all sleeve diameters,

- for sleeves with diameter $\varnothing 60-\varnothing 80 \mathrm{~mm}$ the decreasing trend is maintained up to the compaction temperature of $150^{\circ} \mathrm{C}$, for sleeve diameters $\varnothing 70$ and $\varnothing 80 \mathrm{~mm}$, this tendency is maintained until the compaction temperature of $200^{\circ} \mathrm{C}$, 
- for sleeves with diameters $\varnothing 30-\varnothing 50 \mathrm{~mm}$, the increase of temperature above $100^{\circ} \mathrm{C}$ enables to obtain a much greater degree of compaction.

\section{Conclusions}

Based on the obtained experimental results for compacting triticale, the following general conclusions can be drawn:

- the decrease in the degree of compaction for sleeves with larger diameters may be caused by the fact that greater space inside the sleeve with larger diameter causes a lesser degree of deformation of the straws (one needs to point out that the degree of fragmentation was the same for all sleeves),

- the largest degree of compaction was achieved with sleeves with the smallest diameters (Ø30 mm, Ø40 mm and Ø50 mm), at first, the increase of temperature causes an increase in the degree of compaction; however, for temperatures equal to $150^{\circ} \mathrm{C}$ and $200^{\circ} \mathrm{C}$, we observe an increase of compaction,

- higher straw humidity has a detrimental effect on the degree of compaction, the evaporating water increases the sample volume and negatively affects its durability,

- the lower the humidity of compacted material, the better (recommended humidity is up to $20 \%$ ), recommended processing temperature is $200^{\circ} \mathrm{C}$, this value has a positive effect on the degree of compaction and increases the cohesion of the sample which is beneficial from the standpoint of transport and storage.

In the future, it is planned to expand the examination of compaction degree to include other types of straw, as well as the influence of the degree of fragmentation. The results obtained make for good guidelines for carrying out laboratory testing of compaction using worm screw and piston techniques. In the future, such test results can be employed to formulate an analytical and numerical model of the compaction process. The formulated models will allow to anticipate the energy consumption of the process for calculating the expenses related to the manufacturing of biofuels.

\section{References}

1. K. Talaśka, I. Malujda, D. Wilczyński, Agglomeration of natural fibrous materials in perpetual screw technique - a challenge for designer. Procedia Engineering, Vol. 136, 63-69 (2016)

2. I. Malujda, K. Talaśka, Identification of Thermo-Mechanical Properties of Natural Polymers with a Hybrid Method. Engineering Transactions, Vol. 64, iss. 4, 635-641 (2016)

3. I. Malujda, K. Talaśka, Identification of phenomena accompanying the process of compressing natural polymers. Procedia Engineering, Vol. 177, 369-374 (2017)

4. K. Talaśka, Analysis of the energy efficiency of the shredded wood material densification process. Procedia Engineering, Vol. 177, 352-357 (2017)

5. D. Wilczyński, I. Malujda, K. Talaśka, R. Długi, The study of mechanical properties of natural polymers in the compacting process. Procedia Engineering, Vol. 177, 411-418 (2017)

6. J. S. Tumuluru, C. T. Wright, J. R. Hess, K. L. Kenney, A review of biomass densification system to develop uniform feedstock commodities for bioenergy application. Biofuels, Bioproducts and Biorefining, 5, 683-707 (2011) 
7. C. A. N. Xavier, V. Moset, R. Wahid, H. B. Moeller, The efficiency of shredded and briquetted wheat straw in anaerobic co-digestion with dairy cattle manure. Biosystems Engineering, Vol. 139, pp. 16-24 (2015)

8. P. D. Grover, S. K. Mishra, Biomass briquetting, Technology and practices. Field Document No.46, Bangkok (1996)

9. D. Wilczyński, K. Talaśka, I. Malujda, P. Jankowiak, Experimental research on biomass cutting process. MATEC Web of Conferences 157, 07016 (2018)

10. C. K. W. Ndiema, P. N. Manga, C. R. Ruttoh, Influence of die pressure on relaxation characteristics of briquetted biomass. Energy Conversion and Management, 43, 21572161 (2002)

11.P. K. Adapa, J. Bucko, L. G. Tabil, G. Schoenau, S. Sokhansanj, Pelleting Characteristics of Fractionated Suncure and Dehydrated Alfalfa Grinds. ASAE/CSAE North-Central Intersectional Meeting, Saskatoon, Saskatchewan, Canada, September 27-28 (2002)

12. P. K. Adapa, G. J. Schoenau, L. G. Tabil, S. Sokhansanj, B. Crerar, Pelleting of Fractionated Alfalfa Products. ASAE Annual International Meeting, Las Vegas, Nevada, USA, July 27-30 (2003)

13. Y. Li, H. Liu, High pressure densification of wood residues to form an upgraded fuel. Biomass Bioenergy 19, 177-186 (2000)

14. K. Ishii, T. Furuichi, Influence of moisture content, particle size and forming temperature on productivity and quality of rice straw pellets. Waste Management, Vol. 34, Issue 12, 2621-2626 (2014)

15. V. S. P. Bitra, A. R. Womac, C. Igathinathane, P. I. Miu, Y. T. Yang, D. R. Smith, N. Chevanan, S. Sokhansanj, Direct measures of mechanical energy for knife mill size reduction of switchgrass, wheat straw, and corn stover. Bioresource Technology 100, 6578-6585 (2009)

16. V. S. P. Bitra, A. R. Womac, N. Chevanan, P. I. Miu, C. Igathinathane, S. Sokhansanj, D. R. Smith, Direct mechanical energy measures of hammer mill comminution of switchgrass, wheat straw, and corn stover and analysis of their particle size distributions. Powder Technology 193, 32-45 (2009)

17. A. Sapietová, V. Dekýš, M. Sapieta, P. Pecháč, Application of Computational and Design Approaches to Improve Carrier Stability. Procedia Engineering, Vol. 96, 410418 (2014) 